Archivum, LXX (II), 2020, pp. 263-290

\title{
Estrategias de construcción discursiva del microrrelato en Antonio Pereira: análisis de tres ejemplos ${ }^{1}$
}

\author{
Carmen Morán Rodríguez \\ UNIVERSIDAD DE VALLADOLID \\ carmen.moran@uva.es
}

Recibido: 05/03/2020

Aceptado: 07/05/2020

\begin{abstract}
RESUMEN:
El artículo aborda el análisis de los procedimientos compositivos en tres cuentos hiperbreves de Antonio Pereira (1923-2009): "Una novela brasileña", "Picassos en el desván" y "Pastoral". En ellos pueden verse constantes de la escritura de este autor, tales como el juego entre lo enunciado y lo sugerido, entre realidad y ficción, el alcance metaficcional logrado en unas pocas líneas, el erotismo implícito, y la pericia en la selección de términos y la gradación de emociones a fin de lograr una extraordinaria densidad.
\end{abstract}

PALABRAS CLAVE: Antonio Pereira, cuento español actual, microrrelato, microcuento, microficción, narrativa breve.

1 Este artículo se ha realizado en el marco de las actividades del Proyecto de Investigación «Fractales. Estrategias para la fragmentación en la narrativa española del siglo XXI» (PID2019-104215GB-I00), financiado por el Ministerio de Ciencia e Innovación. Asimismo, forma parte de las investigaciones desarrolladas por el Grupo de Investigación Reconocido Literatura Española Contemporánea (Universidad de Valladolid) y el Grupo de Investigación Consolidado MiRed (Universidad San Pablo-CEU). 


\title{
Discoursive strategies in Antonio Pereira's micro stories: analyzing three examples
}

\begin{abstract}
::
This paper analyzes compositional procedures in three short-short stories by Antonio Pereira (1923-2009): "Una novela brasileña", "Picassos en el desván" y "Pastoral". The three of them shows some of Pereira's most outstanding aspects, such as the game between the stated and the suggested information, between reality and fiction, the metafictional meaning displayed in a few lines, the implicit erotism and a rare skill in the selection and disposition of words and the gradation of emotions, in order to achieve an extraordinary density.
\end{abstract}

KEY WORDS: Antonio Pereira, Contemporary Spanish Short Story, Micro Stories.

Desde que Gullón $(1986,1988,1991)$ reparase en su singularidad y valía, la producción cuentística de Antonio Pereira ha contado con el reconocimiento y la atención de la crítica, dando lugar a una bibliografía amplia y solvente que no se ha detenido tras la muerte del escritor, en 2009, y que ha sido favorecida por la Fundación que lleva su nombre, creada en 2008. Dada la vigencia que en las últimas décadas ha alcanzado la escritura hiperbreve, no es raro que buena parte de las últimas aportaciones bibliográficas se hayan centrado precisamente en ese rasgo.

Ya González Boixo, en el clarificador estudio que precedía a Recuento de invenciones, notaba en el escritor leonés una tendencia a escribir cuentos más breves, a un "progresivo adelgazamiento del texto como consecuencia de la búsqueda de una mayor intensidad en el relato y del desprendimiento de elementos accesorios como pueden ser las descripciones o las divagaciones" (2004, 46). Los títulos publicados por Pereira con posterioridad no hicieron sino confirmar lo advertido por González Boixo, quien al analizar Picassos en el desván (1990) reparaba en la presencia, entre los cuentos breves, de algunos que bien pueden ser considerados microrrelatos, distribuidos "como si el autor quisiera establecer un determinado ritmo de lectura" (González Boixo, 2004, 46). 
Sin embargo, González Boixo advertía: “estos microrrelatos reflejan el carácter siempre innovador de Pereira, aunque hay que reconocer las limitaciones del género. Es cierto que autores como Monterroso o Arreola han ofrecido muestras llamativas, pero, más allá de su ingeniosidad, el lector echa en falta la existencia de un texto más amplio" (2004,47). Seguía en este dictamen el crítico al escritor, quien también manifestaba cierto distanciamiento respecto del cuento hiperbreve como práctica autónoma, al afirmar que la inclusión de esos relatos mínimos es "algo que yo solo concibo como un entreverado de piezas más largas, ya que un libro sólo de este tipo de relatos sería un poco cargante" (cit. en de la Varga Llamazares, 2019, 107).

A pesar de este juicio, algunos de los trabajos más recientes han destacado precisamente estas composiciones más breves de Pereira, señalando su parentesco con la producción poética del autor (Martínez, 2006) o su hibridismo genérico con el poema, el cuento y la anécdota (de la Varga Llamazares, 2019). Incluso, a pesar de que los Cuentos de la Cábila sean algo más extensos, la propuesta de leerlos como teselas de una "novela de cuentos" (Celma Valero, 2016) responde a un prisma de lectura fractal propiciado por la ficción hiperbreve. Y todo ello a pesar de la renuencia de Pereira a otorgar al microrrelato entidad independiente respecto del cuento breve, y a que el número de composiciones que podrían ser considerados microrrelatos no supera la veintena (de la Varga Llamazares, 2019: 107).

La reducción a mínimos del relato propicia, según ya vio Valls (1991), la colaboración del receptor, ese "lector cómplice", dispuesto a completar el sentido de lo que en la enunciación se reduce a un sucinto esquema narrativo, de gran poder de sugerencia, especialmente en lo concerniente a los aspectos eróticos (Valls, 1991; Álvarez Méndez y Encinar, 2019). Además, la reducción de la anécdota redunda en un incremento de la dimensión metaficcional del texto, o, como González Boixo indica, refiriéndose a "Picassos en el desván", que comentaré más adelante: “(...) sin que se pierda la esencia de la historia, se pone 
el énfasis en la contemplación del propio acto creador, ejemplificando el proceso de la escritura en sus pasos iniciales" (2004, 47). Así lo vemos en los tres brevísimos relatos que analizaré a continuación, y que prueban cómo la condensación ficcional de estos textos esconde, bajo su aparente sencillez, complejos procedimientos compositivos.

El primero de ellos, cronológicamente, apareció en Los brazos de la y griega (1982).

\section{Una novela brasileña}

O Capitão do Exército Agenor Araújo de Medeiros, 39 anos, foi assassinado no final de noite ao tentar reagir a um assalto na rua Bertolini, próxima à Praia Branca, em Guanabara. O militar estava no seu carro em companhia de Palmira Fernandes Oliveira quando dois criminosos surgiram de arma empunho. Agenor morreu antes de ser socorrido no Hospital Bom Jesus da Estrela. Era casado com Fernanda Valéria Martins Costa com quen tinha una filha de sete anos. A ocôrrencia ficou registrada. (Pereira, 2012, 243).

Su brevedad resulta decisiva, incluso desde el punto de vista visual: es importante que en el primer golpe de vista el lector repare en la paradoja de que una "novela" no llegue ni siquiera a ocupar toda la caja de escritura de la página. La proyección metaficcional viene dada desde la alusión del género "novela" en el título, que plantea evidente contradicción con la extensión del relato y obliga a leer este en función de unas convenciones de género a la luz de las cuales el sentido se completa con una obvia carga irónica. Se respeta (o se emula) el estilo periodístico sintético y objetivo al consignar los datos. Estos, sin embargo, en su hiperbrevedad, encierran el germen de una historia que podemos adivinar complicada: atraco, intervención de un héroe (honorable, además, por su graduación militar), asesinato de este, consecuencias del crimen -viudedad y orfandad-, y, lo más interesante del todo, por ser algo implícito en lo que el 
lector debe reparar: probable adulterio cometido por ese héroe. Casi una muestra en miniatura de las funciones de Propp, contenidas en una noticia de sucesos de un diario brasileño. Esto se corresponde perfectamente con la idea que Pereira apunta en su diario en julio de 1970:

(...) la novela trata de problemas humanos, y yo creo que estos problemas son más novelescos en los países tensos que en aquellos que pueden permitirse el lujo de relajarse. Leo a Caldwell, La casa de la colina, un relato de malos ámbitos para los humildes. En las primeras páginas se ve inevitable "la novela", puesto que hay una casa aislada, un marido adúltero y borracho, una esposa abandonada e insatisfecha, un vecino joven a la espera... En la sociedad de norte de Europa, con estos mismos elementos, a lo mejor "no hay novela". [...] Ahora mismo no se puede por nuestros pagos hablar de novelas sin tener presente el fenómeno de los hispanoamericanos. La avalancha ha puesto nerviosos a nuestros autores españoles, que de repente quieren hacer alardes de novedad y experimentalismo. $(2019,28)$

El interés no surge de la complicación deliberadamente buscada, sino que puede estar en lo mínimo cotidiano siempre y cuando sepamos dónde mirar. La elección de Brasil no es casual, sino que parte de la implícita consideración de Brasil como "país tenso", categoría que Pereira no desarrolla, pero que podemos identificar con economía en vías de desarrollo, sociedad culturalmente heterogénea y compleja, clima e imaginario imprecisamente tropical, etc ${ }^{2}$. La lengua portuguesa da mayor veracidad

2 Recuerda en cierto modo esta consideración de Pereira sobre las mayores posibilidades novelescas de los países tensos al célebre prólogo de Alejo Carpentier a El reino de este mundo, donde el escritor cubano rechazaba los códigos de lo fantástico desplegados por las vanguardias europeas, a cuyos representantes consideraba taumaturgos devenidos en burócratas, abogando en su lugar por lo real maravilloso que encontraba a cada paso en la cotidianeidad americana. No es esta ocasión para discutir los apriorismos que pueden estar operando tras estos planteamientos, solo de constatar que Pereira mantiene un punto de vista similar. 
al artificio que el escritor pone ante nuestros ojos, pues el texto parece realmente una noticia copiada de la prensa brasileña, aun cuando no lo sea.

La concisión no impide el regodeo en lo puramente narrativo -incluso en la eficacia a la hora de manejar suspense y dramatismo, que son valores propios de la ficción y no de la información, pero que resultan verosímiles en el registro sensacionalista de una página de sucesos: "quando dois criminosos surgiram de arma em punho". De ahí la contradicción entre el género que promete el título ("novela") y la concisión con que se narra la historia. El cierre de la misma, "A ocorrência ficou registrada", es clave, pues apunta a la mencionada dimensión metaficcional: no solo importa el suceso, sino el que este suceso sea contado (y deje de ser realidad para convertirse en escritura). Queda esto reforzado por la ambigüedad del término ocôrrencia, que en portugués significa 'suceso' pero que comparte significante con el español ocurrencia, cuyo sentido es 'fabulación' (y aquí, en efecto, el suceso deviene fabulación, aunque solo si el lector cómplice sabe completar las elipsis).

La pieza se ajusta, pues, perfectamente a lo que el figurado Sabino Ordás le hacía notar a Pereira en la entrevista reeditada después como prólogo a sus Reseñas y confidencias, y sobre lo que el autor abundaba con palabras que cuadran bien a este caso:

S.O.: Encuentro en su narrativa una voluntaria "épica de lo efímero", una huida de toda prosopopeya.

A.P. Creo que en mis fabulaciones no es infrecuente la presencia de criaturas poco brillantes -el héroe legendario es más improbable que el héroe cotidiano-, y también, como consecuencia, el rebaje por la ironía de la aparente grandeza de algunas situaciones. (Ordás, 1985, 11).

En la "novela brasileña" que nos ocupa, más bien, Pereira repara en la grandeza oculta de sucesos que pasan totalmente desapercibidos cada día, y en la posibilidad de que cualquiera 
pueda, en un fugaz instante (acaso el postrero) ser un héroe, pero -como le hace notar Ordás, aunque refiriéndose al protagonista de País de los Losadas - un héroe en el sentido unamuniano, "uno que da ocasión a que se pueda escribir sobre él un poema épico, un epinicio, un cuento, un epigrama o siquiera una gacetilla" (cit. en Ordás, 1985, 1133). La heroicidad, pues, depende del escritor: es este quien convierte al ser humano, perfectamente intercambiable con cualquier otro, en héroe, al escribirlo, al asegurarse de "ficar registrada" la "ocorrência". Para ello no es preciso ni que toda la vida del personaje sea interesante, ni que la obra en la que se le asciende a héroe sea una larga epopeya. No está en la extensión la medida de la valía que una vida humana puede alcanzar, sino en el destello de un instante que merece la memoria. Nada más adecuado, por tanto, que una escritura también breve e intensa. Así, no es raro que, desde esa convicción, Pereira destaque "El Sur" de Borges, cuando tiene ocasión de conversar con el porteño (aunque al ritmo entrecortado y cambiante que este impone en una conversación un tanto frustrante), donde también Dahlmann, cuya vida sería perfectamente inapreciable, alcanza la grandeza en una hora final "humana y caliente" (Pereira, 1985, 26). Bien mirado, el reverso de "Una novela brasileña" en la producción de Pereira sería otro cuento, muy borgiano tanto por su tema como por su formulación irónicamente policiaca: “El caso de la calle cronista Malvide". En él un hombre perfectamente gris es capaz de un crimen gratuito y azaroso solo, precisamente, por ser merecedor de una gacetilla (o, lo que viene a ser igual, de una mención en la sección de casos de un diario local).

3 La cita de Ordás es fiel al sentido, pero ligeramente inexacta. Las palabras de Unamuno, incluidas en su metaficcional relato "Y va de cuento" (El espejo de la muerte, 1913) son: "-¿Qué es un héroe? --Uno que da ocasión a que se pueda escribir sobre él un poema épico, un epinicio, un epitafio, un cuento, un epigrama, o siquiera una gacetilla o una mera frase. Aquiles es héroe porque le hizo tal Homero, o quien fuese, al componer la Iliada. Somos, pues, los escritores --joh, noble sacerdocio! - los que para nuestro uso y satisfacción hacemos los héroes, y no habría heroísmo si no hubiese literatura. Eso de los héroes ignorados es una mandanga para consuelo se simples. ¡Ser héroe es ser cantado!" (Unamuno, 1977, 146). 
Además, aunque la novela no sea verdaderamente entresacada de la sección de sucesos de un periódico, sino más bien una parodia de cierto estilo novelesco en la redacción de noticias de este tipo, Pereira juega aquí al object trouvé, asumiendo como parte de su obra un texto encontrado, e invitándonos a leer un texto convencionalmente no literario como literario. La literatura está en todas partes, basta con saber mirar, parece decirnos el escritor (este proceder, cuyas raíces están en las vanguardias de inicios del siglo XX, ha sido muy utilizado en las últimas dos décadas por autores más jóvenes, asociados a una estética posmoderna: pienso en Vicente Luis Mora, Agustín Fernández Mallo o Javier García Rodríguez, entre otros).

Si en el relato analizado se emulaba mediante un registro creíble una noticia periodística, en el que a continuación analizaremos el proceso se invierte, ya que se parte de una noticia auténtica para construir, con mimbres escuetos, una microficción en la que nuevamente Pereira apunta el esquema narrativo que el lector cómplice sabrá entender. Se trata del texto que da título al volumen Picassos en el desván (1990).

Picassos en el desván

Una vez estaba el novelador en una ciudad lejana y prometedora de fabulaciones cuando tuvo en las manos un periódico de su propio país y en él venía la noticia breve de tres picassos hallados en el trastero del difunto párroco de Priegue en el municipio pontevedrés de Nigrán, o sea, un gouache de la época rosa del pintor más un retrato en madera de su prima María Ruiz más un temple sobre tela con una figura inacabada, y la adquisición tuvo lugar en 1920 (Maura sí) cuando el párroco fue requerido por su ordinario (los exhortos, las audiencias, la sagrada amatista) para que vendiera unas casas de su propiedad sitas en un barrio de Vigo poco acorde con la moral cristiana y el requerido vendió sus casas (los tasadores, el notario) y con los cuartos frescos marchó a París (Monforte, Venta de Baños, Hendaya), el cura de Priegue en el 
París de los hoteles con agua corriente y bidet mercando las obras por 28000 pesetas (el fauvismo, el cubismo, el Moulin Rouge), y el novelador ni caso, busca que buscarás argumento para una novela río. (Pereira, 2012, 403).

En el mismo volumen, Picassos en el desván, aparece el microrrelato "La esquela", en el que el narrador afirma que su fuente es la esquela de la joven "Helena de Fiore de Luna de Pérez de la Plana, condesa de la Plana y de Santarcángelo", que habría muerto "en accidente en La Spezia (Italia) el día 31 de mayo de 1986" (Pereira, 2012, 461). La profusión de datos crea una falsa impresión de veracidad: huelga decir que la mencionada esquela no existe, al menos en las fechas próximas a la que refiere Pereira. Sin embargo, esta misma presunción nos llevaría a considerar ficcional la noticia de los picassos aparecidos en un altillo, que por el contrario sí se basa en una noticia publicada, algo en lo que la crítica no ha reparado hasta la fecha. Tres son los diarios en que apareció: La Voz de Galicia, edición de La Coruña (22/11/1986), ABC (edición de Sevilla, 23/11/1986) y El País (23/11/1986) (véanse las imágenes correspondientes a la noticia en los tres medios, en las figuras 1, 2 y 3 del Anexo).

La redacción de los tres breves difiere poco, aunque las versiones más completas son las de La Voz de Galicia y El País, que remite al diario gallego como fuente. Pereira se basa, muy probablemente en este último medio, si hacemos caso de lo que el cuento afirma: que "el novelador" leyó la noticia en un diario español comprado en el extranjero (donde la difusión de El País es mayor que la de $\mathrm{La}$ Voz de Galicia). Lo primero que llama la atención en este brevísimo relato es la fidelidad de lo narrado en él a lo relatado en la noticia de El País: todos los datos (lugar del hallazgo, nombre del pintor, número de los cuadros, características de estos, sucesos pasados que explicarían la posesión, precio original de las pinturas) son puntualmente fidedignas. ¿Qué añade el cuento, entonces, a la pura verdad de la noticia? El inicio y el final, que enmarcan meta (y auto) ficcionalmente la 
historia, y las brevísimas notas insertas entre paréntesis al hilo de los datos. La apertura y el cierre inmiscuyen a un escritor en tercera persona ("el novelador" que lee el periódico y desdeña las historias, breves y verídicas, pero profundamente literarias, porque anda a la búsqueda de "argumento para una novela río"). El lector inmediatamente identifica a ese "novelador" con el lector de la noticia y con el propio Pereira, a pesar de la evidente (e irónica) distancia impuesta por la tercera persona y la elección del término "el novelador", en lugar de "el escritor" o "el cuentista", que le identificarían de manera más inequívoca (en sus diarios, Pereira se refiere a sí mismo en una ocasión como "el fabulador", $2019,20)$. Aquí la asociación existe, pero sobre ella se impone una distancia de gran calado irónico. Consideremos que Pereira solo aparece ante sus lectores como autor de tres novelas, todas ellas anteriores a este volumen (Un sitio para Soledad, 1970; La costa de los fuegos tardíos, 1975; País de los Losadas, 1978), y que nunca se mostró completamente cómodo en esta faceta de novelista (de hecho, del segundo de los títulos mencionados se manifiesta insatisfecho en varias ocasiones). Sin embargo, si había probado suerte con el género novelístico es porque percibía en este un mayor reconocimiento canónico que en el cuento, percepción de la que sin embargo se distancia definitivamente a la altura de la publicación de Picassos en el desván. La elección del sintagma "novela río" como objetivo del novelador ajeno a los hallazgos literarios que le salen al paso en las noticias, culmina el tono irónico ya anunciado: se trata de un calco del francés roman fleuve, propio de la crítica postestructuralista francesa que tan en boga había estado en los años 70 y que en España había encontrado eco; se denominaba "novela río" al proyecto narrativo de grandes dimensiones (en el espacio y en el tiempo), en las antípodas de la narrativa breve de Pereira, quien parece aquí satirizar su anterior faceta de "novelador", alejándose definitivamente de esa ella (de ahí la tercera persona) y optando (el propio texto es la paradójica prueba) por el relato breve o, como en este caso, hiperbreve. En varios lugares explica Pereira su preferencia por el cuento sobre 
la novela (por ejemplo, en Pereira, 1995, 169). Pero resulta especialmente llamativa la forma en que defiende tal preferencia ante Sabino Ordás, rechazando la actitud de esos críticos que solo valoran el cuento como antesala de la obra verdaderamente importante -que, por supuesto, deberá ser una larga novela, críticos que le elogian "[con] la esperanza de que sí, que pronto, acaso, llegará la novela grande-grande que cabe esperar del promisorio autor, la novela -total-... ¡Pero es que yo no tengo ninguna gana de escribir la novela total!" (Ordas, 1985, 11-12). El sintagma "novela total", aquí en la voz del Pereira-autor, equivale al de "novela-río" que el Pereira-narrador atribuye a ese "novelador" que bien puede haber sido él mismo unos años atrás, cuando su negativa frente a esos críticos no era tan firme.

Este microcuento es la demostración de que una historia no vale solo por lo que cuenta, sino también por lo que deja de contar, pero sugiere; es, por tanto, una defensa del cuento no solo breve, sino también denso. Dicha defensa se manifiesta en esas notas entre paréntesis que apuntan todo lo que en la parquedad de la noticia no puede desarrollarse, pero sí en la fantasía del lector o en el relato. Sin embargo, Pereira opta por no desarrollar esas sugerencias entre líneas, sino apuntarlas tan solo, como si de un borrador se tratase, para que sea el lector quien complete, $y$, sobre todo, para demostrar que en los relatos hiperbreves, aunque no aparezcan, como en este, explícitamente, siempre se dan esos paréntesis que el lector adivina tras este o aquel término. Son notas parentéticas que siguen a una palabra, apuntando todo lo que esa palabra sugiere con su sola mención; las notas nunca forman frases desarrolladas, no tienen verbo: "1920 (Maura sí)", “...fue requerido por su ordinario (los exhortos, las audiencias, la sagrada amatista)", "vendió sus casas (los tasadores, el notario)", “...marchó a París (Monforte, Venta de Baños, Hendaya)", "el cura de Priegue en el París de los hoteles con agua corriente y bidet mercando las obras por 28000 pesetas (el fauvismo, el cubismo, el Moulin Rouge)". Estas notas, además, enfatizan el contraste entre lo local (Priegue) y el cosmopolitismo parisino, 
contraste al que se suma, en el plano metaficcional, el del novelador (local) que lee la noticia en el extranjero, uniéndose de esta manera, como han señalado Álvarez Méndez y Encinar, "lo exótico al arraigo, lo desconocido a lo conocido" $(2019,11)$.

Es preciso reparar en la deliberada pobreza de puntuación empleada en la relación de los hechos, a fin de que resulte evidente que se enumeran de forma objetiva y sin ornato literario datos precisos de una noticia; lo más divertido de todo es que los juegos e incluso la ausencia de puntuación eran muy característicos de las novelas experimentales herederas de la novela río, que en los años 70 y aun 80 habían deslumbrado a tantos narradores. Pereira, por otra parte, es muy consciente de su peculiar uso de la puntuación, que algunos quebraderos de cabeza le dio con sus editores, según consigna en sus diarios $(2019,95)$.

Pese a esa aparente objetividad en los hechos que se relacionan, el narrador se las arregla para filtrar la subjetividad, asumiendo el punto de vista del párroco, es decir, dando vida a "la ficción de una voz", que Pereira consideraba esencia del cuento ${ }^{4}$. Aunque el cuento está construido como narración heterodiegética en tercera persona, esta voz se manifiesta en las aclaraciones parentéticas (donde vemos qué le supuso al párroco la orden del obispo, qué la venta de las casas...), y en determinados modismos que identificamos con el registro dialectal verosímil de un párroco del Noroeste ("marcho" por "se marchó", "cuartos" por "dinero"). La subjetividad se hace patente también en la precisión "el París de los hoteles con agua y bidet". Con este complemento, que, por supuesto, no estaba en la noticia original, se elige de entre todas las facetas de la ciudad de la luz, la de una libertad sexual democratizada e institucionalizada. Lo mismo sucede con

$4 \mathrm{Al}$ frente de la selección personal de relatos Me gusta contar, Pereira situó un "Decálogo para cuentistas" cuyo punto 7 reza: "Explotar la voz imaginada del narrador, un cuento es la ficción de una voz" (1999, 11); en este caso -y también en el siguiente que analizaremos, "Pastoral" - , la voz ficcional del narrador se modula para permitir que escuchemos la del personaje, cuyo punto de vista y registro se asume a pesar de la heterodiégesis. 
la enumeración de los movimientos artísticos que interesarían al párroco a la hora de gastar sus 28000 pesetas: junto con "el fauvismo, el cubismo", se cuela -en tercer y definitivo lugar- el espectáculo tentador del Moulin Rouge. Es, en definitiva, el punto de vista de un párroco de Priegue extasiado ante bidés y coristas el que subrepticiamente, como si dijéramos entre líneas (pero, en realidad, mediante una precisa selección de los componentes de esas líneas), hace presente una voz en esta ficción.

Al igual que sucedía en "Una novela brasileña", "Picassos en el desván" contiene una metaficcionalidad implícita, al contener el breve cuento dos planos: el del "novelador", persona al que el lector identifica con Pereira, y el de lo relatado en la noticia. A esto se añade que las notas parentéticas evidencian la intervención de un narrador distinto al "novelador" (que se distancia de él en las últimas palabras del cuento, "el novelador ni caso, busca que buscarás argumento para una novela río"), dando al texto la consistencia de un "esquema narrativo" que hace al lector consciente del artificio verbal que tiene ante sí. Y es que, como ha señalado la escritora Care Santos en su comentario a este relato, quince líneas pueden bastar para escribir una novela río (en Álvarez Méndez y Encinar, 2019, 202).

"Picassos en el desván" es, pues, toda una poética del microrrelato, que va más allá de la reivindicación práctica de la brevedad, y le suma la densidad de sugerencias y la elección de un asunto cotidiano de entre la realidad que rodea al escritor en contextos aparentemente no literarios. Esto, que en "Una novela brasileña" se enunciaba en el plano textual, tiene además ahora un refrendo en el plano extratextual, pues se trata, esta vez sí, de una noticia rastreable en la prensa.

El tercer ejemplo que analizaré procede de La divisa en la torre (2007), último volumen de cuentos publicado en vida de Antonio Pereira. En este título la perceptible tendencia a la brevedad que ya había notado González Boixo al presentar Recuento de invenciones se incrementa, y son numerosos los relatos que no llegan a las dos páginas. En gran parte de ellos, además, el molde genérico 
del cuento breve o el microrrelato se superpone al de la anécdota, género literario menor y ausente por lo general de los manuales, pero de antigua tradición, y acaso antecedente del microrrelato. Así lo señala, basándose en Tejero Alfageme (2002), el trabajo de Raquel de la Varga Llamazares, que señala cómo muchos de los cuentos breves de La divisa en la torre se presentan como anécdotas, reales o inventadas, pero con concurrencia de personajes reales citados casi siempre por su nombre y apellidos y, en cualquier caso, bien reconocibles. En ellas el narrador puede tener un papel de mero testigo, pero "identificado en todo momento con Antonio Pereira" (de la Varga Llamazares, 2019, 113), de manera que el libro termina por tener una unidad de sentido, el autobiografismo, aunque entendido de una manera fundamentada en el fragmentarismo y la elipsis (Rosell, 2009, 492).

Esto no significa, sin embargo, que todos los cuentos integrados en La divisa en la torre respondan a esa forma de la anécdota personal donde la identificación del narrador con Pereira es una invitación explícitamente tendida al lector. Algunos no poseen per se ese estatuto autorreferencial, aunque sí es cierto que, por tratar motivos recurrentes en Pereira, a la altura de 2009 están de alguna manera impregnados por su sello personal, como si en un giro casi manierista Pereira volviese, ante sus lectores fieles, a sus temas de siempre. Es este el caso del relato que analizaré en último lugar, una pieza maestra: "Pastoral".

\section{Pastoral}

Era un hombre como cualquier otro de los que ves por la calle, solo que este iba encogido en ropas reverendas que parecían pesarle.

A mitad del viaje preceptivo, ya en el territorio de las minas, le apuraba la próstata y se apeó del coche en el lugar que le pareció más a salvo, pero lo vieron y desde unos desmontes de la hulla bajaron voces de burla:

“QQue se la corten!” “QQue se la corten!” 
“Vaya por Dios", y por primera vez se miró con ternura aquella cosilla que en una larga vida solo le había servido para evacuar. El secretario esperaba junto a la portezuela entreabierta, pero el hombre de las ropas reverendas se detuvo y trazó la señal de la fe hacia los hombres del carbón, y es probable que ellos vieran allá abajo no más que un resplandor fugaz, sin saber que lo daba la amatista, sin saber qué es una amatista.

(Pereira, 2012, 762).

El argumento -la anécdota más bien - es sumamente sencillo: un sacerdote -que suponemos de cierto rango, pues le acompaña un secretario - siente la necesidad de orinar en pleno viaje por el Noroeste, esa región dilecta a Pereira; concretamente, en la zona de las minas. Detiene el auto en un lugar que cree a salvo de las miradas indiscretas, pero cuando ya está en plena acción (en plena micción), oye las imprecaciones burlonas de los mineros, quienes gritan (aquí irrumpe en el relato, con enorme efectividad, el estilo directo): “iQue se la corten!”. El sacerdote, contemplando la parte aludida, experimenta un sentimiento que debe ser de melancolía o nostalgia, pero en el que el narrador no abunda. Entonces, mirando hacia los mineros, hace la señal de la cruz. El narrador aventura que probablemente los mineros no viesen más que "un resplandor fugaz", el de la amatista (se entiende que del anillo del prelado), sin saber qué era.

Este resumen es tan exacto y fiel como abismal la distancia que lo separa de la maestría del relato, patentizando la diferencia entre dos historias que, en rigor, parecen contar lo mismo, pero no. Y es que, como los poemas, los cuentos $-\mathrm{y}$ más cuanto más breves son - se hacen con palabras, no con ideas. El genio está en los detalles, en elegir las palabras exactas y omitir las esperables, confiando a la inteligencia del lector el interpretar adecuadamente las connotaciones de cierto término, la ausencia de otros, las asociaciones semánticas que pueden establecerse entre ellos...

Para empezar, comprobamos que en el relato de Pereira en ningún momento aparecen las palabras "cura" o "sacerdote" - 
menos aún "obispo". El narrador ha evitado cuidadosamente toda denominación concreta para referirse a la dedicación que adivinamos en el innominado protagonista; en su lugar, se refiere a él solo en dos ocasiones, y en ambas lo hace como "hombre" ("Era un hombre", "el hombre"). La información -absolutamente imprescindible para comprender el sentido del cuento- acerca de su profesión religiosa nos la da a través del adjetivo que acompaña a su indumentaria: "ropas reverendas", y mediante la mención final del anillo de amatista, que precisa aún más, pues nos indica que se trata, muy probablemente, de un obispo. Así que tenemos una omisión cuyo efecto es, al menos, múltiple: 1) al referirse al personaje como "hombre", se enfatiza su cualidad de humano, sin distinción de estado; 2) pero, evidentemente, "hombre" hace referencia a la condición de vir, asociada a la sexualidad -virilidad - que en este personaje, por su condición, no se manifiesta normalmente; 3 ) además, aunque desde el comienzo hemos podido suponer, por la referencia a la indumentaria, que se trata de un sacerdote, nada nos ha permitido sospechar que se tratase de todo un obispo, ya que repetidamente el narrador se las arregla para envolver a su criatura de un halo de insignificancia: "Era un hombre como cualquier otro de los que ves por la calle, solo que este iba encogido en ropas reverendas que parecían pesar$l e^{\prime \prime}$. Es decir, no solo era corriente, como cualquier otro, sino menos incluso que cualquier otro. Es muy interesante esta mención a las vestiduras talares, pues con ser tan breve tiene una enorme densidad connotativa, debida, por una parte, al doble sentido del verbo "pesar" ('tener gravedad o peso', 'tener mucho peso' y 'causar arrepentimiento o dolor'), y por otra, pueden activar en el lector una referencia intertextual soterrada, que no se hace explícita pero que el buen conocedor de la literatura española (y del Noroeste español, además) no puede dejar de advertir: el repetido "pesar" que a Don Fermín de Pas, Magistral de la Catedral de Oviedo en La Regenta, le infligen sus ropas, y que le lleva a repetirse, precisamente en los momentos en que se siente más hombre y menos cura: "un hombre con faldas". La introducción 
del tú impersonal ("de esos que ves") es, por una parte, un rasgo de la lengua oral (Senabre, 2011: 67-69), propio del cuento tradicional o, más adecuadamente si tenemos en cuenta el tono de $L a$ divisa en la torre, de la anécdota, e interpela directamente al lector, involucrándolo más en el relato.

Los antagonistas de este brevísimo cuento son aludidos de una manera todavía más evasiva. La primera vez que se les introduce en el relato no se emplea ninguna denominación, sino que el único indicio de su presencia es una forma verbal: "lo vieron". Ninguna precisión sobre ese sujeto múltiple, "bajaron voces de burla"; obsérvese el hábil cambiazo que el escritor nos da en el sujeto de estas dos frases coordinadas copulativas: en la primera, el sujeto del verbo "vieron" es un "ellos" no por casualidad elidido; en la segunda, si siquiera eso, pues el sujeto de "bajaron" es "voces de burla" -así, sin artículo ni determinado ni indeterminado. Un antagonista, pues, plural e informe, casi deshumanizado -no solo porque la distancia física impide al protagonista, suponemos, saber cuántos son o ver sus rostros, sino porque efectivamente aparecen como una agresión o una amenaza colectiva, y por ello mismo más hiriente. Pese a que, como digo, no se aclara quiénes lo vieron, ni de quiénes son las voces, algo nos ha permitido conjeturarlo, y es la precisión física "desde unos desmontes de la hulla", complemento circunstancial donde la elección de los artículos -indeterminado primero, "unos"; determinado después, "la" - es un ejemplo magistral de dosificación de las informaciones implícitas: quedamos enterados de que en ese paraje en cuestión los desmontes son frecuentes, y de que se deben a un agente causante del que nada más hay que explicar, porque su sola mención lo dice todo, "la hulla", con el artículo determinado que únicamente utilizarían quienes están familiarizados con el material en cuestión y la forma de vida que su extracción impone, y dan ese conocimiento por compartido con el receptor, algo que actúa como una captatio, acentuando el compromiso de entendimiento del lector con lo leído. Solo más adelante, próximo ya el desenlace, encontramos una precisión explícita. Y curiosa- 
mente, esta se formula como "los hombres del carbón", en simetría con la reiterada presentación del protagonista como "hombre". De nuevo constatamos que no aparece nunca el término "mineros", que sin embargo viene inmediatamente a la mente del lector -con todas los sobreentendidos culturales aparejados: bulliciosos, pendencieros, montaraces, guasones y, desde luego, anticlericales.

Resulta digno de señalar el realismo de la exclamación “iQue se la corten!", repetida e imaginamos, coreada rítmicamente por los mineros ${ }^{5}$. Es trasunto fiel de la lengua hablada la omisión del término tabú, sustituido pudorosamente tras ese pronombre de objeto directo "la"; pero a la vez que traslada de forma realista la lengua coloquial, tiene gran rentabilidad literaria, pues precisamente la ocultación hace que hacia ahí se dirija toda la atención del lector.

Y la respuesta mental del protagonista, “iVaya por Dios!”, es, de nuevo, sencilla y plenamente ajustada al lenguaje cotidiano. Pero por eso mismo su densidad queda multiplicada exponencialmente. Por una parte, el narrador tiene buen cuidado de especificar a qué se refiere esa exclamación: podemos interpretar que es contrariedad por haber sido visto pese a sus cuidados; pero podemos interpretar también que ese pesar anticipa la melancólica contemplación de la renuncia que su condición sacerdotal ha supuesto. Y no es un detalle sin importancia que la interjección lexicalizada que el escritor elige poner en los labios de su personaje sea "Vaya por Dios", pues al fin y al cabo ha sido este,

5 No puedo dejar de anotar aquí la coplilla, bien conocida en Asturias y León, “Ay, que a los curas les capan este año / quiera Dios que no capen al mi amo / que me tién prometias unas medies / y si me lo capan me quedo sin elles. / Ay que me lo capan / me lo van capar / y yo sin las medies non puedo pasar". El propio Pereira cita esta letra, incompleta y con alguna variante, en una entrada de su diario correspondiente a enero de 1992 (2019, 274-275). Al parecer, en el banquete del premio "Leonés del año", como estaba presente el obispo, alguien la canta, como "provocación ingenua", más festiva que hiriente. Pereira asegura saber quién, pero no lo anota, aunque las pistas ("es orbigués, es ex ministro") nos permiten identificar al cantarín comensal con Manuel Núñez Pérez, nacido en Benavides de Órbigo y ministro de Sanidad durante la presidencia de Leopoldo Calvo Sotelo. 
Dios, la causa de tal renuncia, y a quien se ofrece ("vaya por..." es una construcción que también significa eso, ofrecimiento de un sacrificio).

El crescendo del relato -de apenas once líneas - nos conduce a un primer clímax, que surge de la contemplación, con ternura, de "aquella cosilla que en una larga vida solo le había servido para evacuar". Vemos aquí, de nuevo (ya lo habíamos encontrado en "Picassos en el desván"), la asunción del punto de vista del protagonista por el narrador. Esta se logra sin introducir estilo directo ni ningún verbo de pensamiento que así lo indique: es indudable que la subordinada adjetiva "que en una larga vida solo le había servido para evacuar" no es una apreciación objetiva del narrador, sino una filtración subjetiva del personaje, cuya mirada de "ternura" queda así explicada. También la elección de ese término "ternura", es cualquier cosa menos inocente: si bien miramos, lo esperable hubiese sido "melancolía" (ese es el sentimiento que transmite su reflexión inmediata sobre toda una vida de castidad), pero en su lugar se prefiere "ternura", menos obvio, mucho más subjetivo, y que además de significar 'sentimiento de cariño entrañable', contiene también el sema de 'blandura', que de manera nada ingenua se desliza precisamente en ese momento climático. Resulta harto elocuente, por cierto, comparar este detalle del cuento con las consideraciones que Pereira hace en sus diarios, a la altura de junio de 1973, acerca de la indefensión y estorbo de los órganos sexuales masculinos, "un defecto de la Creación: esos frutos del hombre se han quedado ahí colgando, mal defendidos" (2019: 59).

A partir de este momento, lo que resta de relato es una única oración, compuesta por cuatro frases coordinadas: "pero $[\ldots]$ y $[\ldots]$ y $[\ldots]$ ". El inicio supone un descenso brusco de la tensión narrativa, con una enunciación que en apariencia es puramente informativa, denotativa "El secretario esperaba junto a la portezuela entreabierta". Sin embargo, la mención de ese secretario modifica la que previamente habíamos descodificado, y el sacerdote apabullado por sus ropas (por su vocación y por las 
renuncias que esta ha supuesto) aparece, simplemente por la mención de ese "secretario", investido de una nueva dignidad, que más adelante se nos confirmará definitivamente, con la última palabra del relato, clave absoluta del mismo. En la tercera frase coordinada de la oración, el narrador desvela el gesto final del protagonista ("trazó la señal de la fe hacia los hombres del carbón"), un gesto mudo dirigido a una colectividad enfrentada a él, que mal podrá comprender su sentido de perdón y redención. Y un gesto que, de nuevo, evoca en el lector una referencia intertextual poderosa: el final de la obra Divinas palabras, de Valle Inclán, cuando el sacristán Pedro Gailo pronuncia ante el pueblo furioso la sentencia de perdón "Qui sine peccato est vestrum, primus in illam lapidem mittat", logrando así aplacar sus iras. Pero en este caso, el ademán sagrado resulta "probablemente" estéril (mediante el adverbio "probablemente" el narrador nuevamente da muestras de no ser omnisciente, sino de tener asumido el punto de vista parcial del protagonista). Y resulta estéril porque desde el desmonte lejano ("allá abajo") en que se encuentran los mineros -nombrados solo por un "ellos" que los aleja, no solo física, sino sobre todo emocionalmente-, habrán visto, en todo caso, "no más que un resplandor fugaz, sin saber que lo daba la amatista, sin saber qué es una amatista". Y así, de manera casi accesoria, en las dos subordinadas adverbiales yuxtapuestas que cierran esa larga oración final de cuatro oraciones coordinadas, llegamos al último y definitivo clímax narrativo de esta pieza maestra, donde de nuevo el narrador asume la perspectiva (y el estado emocional) del personaje, transmitiendo su desdén o su desánimo en esas dos yuxtapuestas que siguen una gradación anímica descendiente: "sin saber que lo daba la amatista, sin saber qué es una amatista". Se trata de un final de gran efecto sonoro, logrado fundamentalmente gracias a dos figuras retóricas iterativas, la anáfora "sin saber..." / "sin saber..." y la epífora "...una amatista" / "...una amatista", acentuado paralelismo que se altera mediante una variatio en la sintaxis, ya que aunque las dos subordinadas dependientes del verbo saber comienzan por 
"que"/"qué", en el primer caso estamos ante una subordinada de objeto directo, interrogativa indirecta, y la segunda otra subordinada de objeto directo, pero con la forma de interrogativa directa, de manera que el paso de la enunciación indirecta a la directa actúa como un rápido zoom sobre la acción y sobre el estado del protagonista. Además, mientras que la primera frase es un endecasílabo a maiori (con acento en sexta) y concretamente un melódico puro, es decir, con acento en la $3^{\underline{a}}, 6^{\underline{a}}$ y $10^{\underline{a}}$ sílabas ("sin sabér que lo dába lamatísta"); la segunda oración sin embargo está formada por una secuencia trisílaba y una decasílaba, bien separadas por el fuerte acento del interrogativo "qué". Esta combinación, propia de la silva, imprime un ritmo marcadamente lírico al desenlace, acorde con su contenido melancólico. La iteración subraya el papel fundamental de la amatista, que simbólicamente encierra todo el asunto del relato: el lector debe descifrar que esa amatista que brilla fugazmente al trazar la señal de la cruz es la del anillo que lleva el protagonista, y que confirma lo que ya antes la mención del secretario nos había hecho sospechar, es decir, que se trata de un prelado de cierta categoría, con toda probabilidad de un obispo, distinguido por el anillo pastoral que simboliza, claro está, los esponsales con la Iglesia (y la consecuente renuncia a la carne). Cobra ahora todo su sentido el título de esta breve pieza ${ }^{6}$, que juega dialógicamente con los varios significados del término pastoral: se trata de una escena en el campo, los mineros tienen el comportamiento jocoso y algo brutal que tradicionalmente se asigna a los pastores, y el protagonista es, por otra parte, un pastor que actúa como tal también frente a esa grey que ha hecho escarnio de él, investido (o mar-

6 Los tres ejemplos analizados (especialmente el primero y el último) muestran la importancia conferida por Pereira al título como parte constitutiva (y a menudo clave) del relato. Es interesante, a este respecto, lo que apunta en su diario en febrero de 1972: compartiendo mesa y conversación con el pintor asturiano Orlando Pelayo, el escritor ha elogiado uno de los títulos de sus cuadros tanto como el propio lienzo; Pelayo no solo no se ofende, sino que señala: "Magritte defendía que el cuadro es igual a la pintura más el título", opinión en la que Pereira está plenamente de acuerdo (2019: 140). 
cado) por su anillo pastoral. La amatista -piedra especialmente frecuente en los anillos episcopales - es una piedra asociada a la castidad y la templanza ${ }^{7}$, virtudes ambas que caracterizan a nuestro protagonista. Esa amatista sirve de réplica simbólica a "aquella cosilla", y también a la "hulla" de los mineros, con la que establece un contraste que metonímicamente representa la oposición entre la renuncia a la carne del obispo y el parrandero y un tanto agresivo espíritu de los mineros. El tema del cuento sería esa súbita revelación de tristeza que sobreviene al obispo tras ese episodio aparentemente insignificante, y que procede no solo de cierta nostalgia de lo nunca vivido -a causa de su voto de castidad-, sino también de la constatación de que su poder y dignidad como obispo poco cuenta fuera del claustro, donde pesa más la virilidad que sus ropas entorpecen y donde se desconoce qué es y qué significa una amatista.

El tema no es nuevo en Pereira. Muchos de sus cuentos representan ese desencuentro entre las aspiraciones y la realidad de lo logrado, que se hace súbitamente patente a causa de un episodio en apariencia trivial, y que a menudo se materializa en un objeto. Concretamente, encuentro una semejanza en la formulación de este cuento y "El apartamento", incluido en Las ciudades de Poniente (1994) (2012, 498-501), donde el narrador acompaña a un obispo a ver el piso que este piensa comprar para su jubilación; se trata de un apartamento modesto en una zona moderna de la ciudad, y la situación resta, a los ojos del narrador, todo el halo de grandeza, distinción y orgullo que acompañaba hasta entonces al prelado, aunque en este caso los recuperará, al menos en parte, al regresar e invitar al narrador a una botella de vino de las que expresamente para él manda todos los años una familia noble local. En el caso de "El apartamento", la vivienda encarnaría simbólicamente la devaluación del prestigio del prelado, mientras que la botella vendría a reestablecer, en parte al menos,

7 Etimológicamente, amatista procede del griego, a-méthystos, 'que no embria$\mathrm{ga}^{\prime}$, y ese significado tampoco parece ajeno al comportamiento del obispo del cuento, sobre todo frente a sus dionisiacos antagonistas. 
el orden inicial. En "Pastoral", el anillo es el objeto que encarna simbólicamente no solo aquellos valores que la tradición le asigna, sino las aspiraciones o frustraciones de un personaje en un momento crucial en el que se viene a resumir y concentrar toda su vida.

En su concisión, "Pastoral" encierra toda la profundidad de una epifanía. Como sabemos, epifanía es un término procedente del griego que significa "manifestación súbita de la divinidad". Pero en literatura, fue otro escritor del Noroeste -de un Noroeste más lejano, pero en cierta forma común al de Pereira- quien entendió que la literatura es una forma de que lo trascendente continúe revelándose a los seres humanos, casi siempre a través de lo nimio. Me refiero a James Joyce, quien hizo de este concepto una noción central en su obra. Aunque Joyce nunca llegó a definirlo, la epifanía sería una súbita revelación trascendente para el sentido de la vida de un hombre que, sin embargo, tiene lugar ante un suceso en apariencia cotidiano, trivial o incluso vulgar. Como los de Joyce, muchos cuentos de Pereira son epifanías que a menudo (y también esto aproxima a estos dos paisanos del Noroeste) no suponen cambio alguno en la vida de sus protagonistas, a quienes frecuentemente abandonamos en un final abierto -analizó algunas muestras Senabre (2011,35-45) -, semejantes a esos finales de los cuentos de Joyce (en especial, me resulta emocionante la melancólica semejanza entre "Los muertos" y "Mientras viene el trenillo", 2012, 171-176). "Pastoral", como también “Una novela brasileña" y "Picassos en el desván”, muestra una súbita epifanía -que en los otros dos ejemplos es de carácter metaliterario, pues ilumina al escritor sobre la naturaleza de lo literario y la capacidad de lo breve para encerrar lo inmenso. Por otra parte, en los tres cuentos observamos el discreto erotismo habitual, aunque nunca demasiado explícito, en los cuentos de Pereira, en cuyas páginas abundan los "personajes ávidos de lo sensual” (Álvarez Méndez y Encinar, 2019, 11). Los tres ejemplos son la demostración palmaria de esa capacidad para que lo erótico quede apuntado (y subrayado) precisamente por soslayarse 
su verbalización explícita: en "Una novela brasileña" adivinamos que el crimen fortuito ha revelado un affair extramatrimonial. En "Picassos en el desván" los cuadros son la prueba del comportamiento de un párroco, díscolo por partida doble en lo moral, pues posee una casa en un barrio de mala nota, y con el dinero de la venta se va a París, donde el narrador le imagina fascinado por la pecaminosa carnalidad latente en lugares (el Moulin Rouge) y objetos (el bidé). En "Pastoral", curiosamente, lo erótico desempeña un papel primordial, pero bajo la variante de su negación. Sería este relato representante de ese "erotismo diocesano" que Ramón de Garciasol atribuía a su amigo Pereira, según él mismo contaba (Pereira, 1982, 170) - en este caso, "diocesano" en su manifestación más literal.

Los tres cuentos analizados muestran, en fin, el ambiguo juego entre realidad y ficción, entre lo sugerido y lo explícito, entre inter e intratextualidad y entre la fabulación y su alcance metaficcional. Sirva este largo, pedestre y acaso tedioso ensayo de contraste con la gracia y el acierto impares de un escritor nunca suficientemente reivindicado.

\section{Referencias bibliográficas}

Álvarez Méndez, N.; Encinar, Á. (eds.) (2019) Antonio Pereira y 23 lectores cómplices, León, Eolas, 2019.

González Boixo, J. C. (2004) “Introducción”, en Pereira, Antonio, Recuento de invenciones, Madrid, Cátedra, 11-56.

Gullón, R. (1986) “Una comedia humana de bolsillo", Ínsula 470-471, 6. Recurso en línea: http://cabila.unileon.es:8383/greenstone3/sites/localsite/collect/producci/index/assoc/HASH01bf/8a0660fa.dir/doc.pdf [18/02/2020].

Gullón, R. (1988) "El ingeniero Balboa y otras historias civiles", ABC Literario, 12/11/1988. Recurso en línea: http://hemeroteca.abc. es/nav/Navigate.exe/hemeroteca/madrid/abc/1990/08/11/051. html [01/03/2020].

Gullón, R. (1991) "Picassos en el desván", ABC Literario, 23/2/1991. Recurso en línea: http://hemeroteca.abc.es/nav/ 
Navigate.exe/hemeroteca/madrid/abc/1991/02/23/059.html [09/02/2020].

Celma Valero, M.ํㅜ P. (2016) Realidad y ficción en Cuentos de la Cábila, León, Universidad de León.

Martínez, J. E. (2006) “Microrrelatos y poesía. El caso de Antonio Pereira" [Texto de la conferencia pronunciada en 2006]. Recurso en línea: http://cabila.unileon.es:8383/greenstone3/library/ collection/producci/document/HASH01c648f14bc04fd164e5ae8d;jsessionid=722071395 AED762F49D463ADAC61070A [09/02/2020].

Ordás, S. (1985) "A modo de Prólogo. Sabino Ordás entrevista a Antonio Pereira", en Pereira, Antonio, Reseñas y confidencias, León, Diputación provincial de León, 1985, 7-16. Texto aparecido originariamente en Pueblo literario, 25-5-1979. Recurso en línea: http://cabila.unileon.es:8383/greenstone3/sites/localsite/ collect/producci/index/assoc/HASH06a0/31bd08b0.dir/doc.pdf [22/02/2020].

Pereira, A. (1982) "Nota con algunos nombres", Los brazos de la i griega, Oviedo, Noega, 170.

Pereira, A. (1985) Reseñas y confidencias, León, Diputación Provincial de León.

Pereira, A. (1990) Picassos en el desván, Barcelona, Mondadori.

Pereira, A. (1994) Las ciudades de Poniente, Madrid, Anaya \& Mario Muchnik.

Pereira, A. (1995) "Reflexiones de un escritor de cuentos", en Santonja, Gonzalo (ed.), Actas del Congreso Internacional de escritores castellano leoneses, hispanoamericanos y portugueses, Valladolid, Sociedad V Centenario Tratado de Tordesillas, 167-170.

Pereira, A. (1999) "Prólogo", Me gusta contar, Barcelona, Mario Muchnik, 9-11.

Pereira, A. (2007) La divisa en la torre, Madrid, Alianza.

Pereira, A. (2012) Todos los cuentos, Madrid, Siruela.

Pereira, A. (2019) Oficio de mirar (andanzas de un cuentista, 1970-2000), Valencia, Pre-Textos. 
Rosell, M. (2009) “Autobiografías mínimas: la invención del yo en una página", S. Montesa (ed.), Narrativas de la postmodernidad. Del cuento al microrrelato, Málaga, AEDILE, 489-500.

Senabre, R. (2011) Antonio Pereira y el arte de narrar, León, Universidad de León.

Unamuno, M. de (1977) El espejo de la muerte, Madrid, Espasa-Calpe [1913].

VALls, F. (2015) "El microrrelato como género literario", en Ette, O; Ingenschay, D.; Schmidt-Welle, F.; Valls Taberner, F. (coords.), MicroBerlín: de minificciones y microrrelatos, Madrid/ Fráncfort, Iberoamericana/Vervuert, 21-49.

VARga Llamazares, R. DE la (2019) “La frontera entre géneros en la ficción hiperbreve de Antonio Pereira", Microtextualidades 5, 106-115. Recurso en línea: https://revistas.uspceu.com/index. php/microtextualidades/article/view/152 [18/02/2020]. 


\section{ANEXO}

\section{Tres cuadros aparecidos en un trastero de Nigrán son obra de Picasso}

Nigrán (Corresponsal). Tres cuadros aparecidos hace algún tiempo en la parroquia de Priegue, del municipio de Nigrán, son obra de Picasso, según un informe del crítico de arte Ramón Faraldo, que ha estudiado las obras. Los lienzos son un "gouache» de la época rosa, un retrato sobre madera de María Ruiz,

na del pintor, y un temple so.. tela de una figura inacabada.

Ramon Faraldo, expresamente autorizado por la Asociación de Criticos de Paris para catalogar la obra de Picasso - de quien fue amigo personal - ha afirmado que no existen dudas sobre la autoría de los lienzos. Éstos aparecieron recientemente, cuando los herederos del sacerdote hicieron limpieza en el trastero de la casa.

La adquisición de las telas se remonta al año 1920, cuando el párroco de Priegue fue requerido por el obispo de la diócesis para que pusiera en venta unas casas de su propiedad situadas en una zona de Vigo poco acorde con la moral católica. Poco después, el sacerdote viajó a París y empleó parte del dinero ( 28.000 pesetas) en la compra de tres pequeñas obras pictóricas.

Figura 1. La Voz de Galicia (La Coruña) 22/11/1986. 
A B C / 49

\title{
Descubiertos en Galicia tres cuadros de Picasso
}

Santiago. S. C.

Tres cuadros del pintor malagueño Pablo Picasso han sido hallados en el trastero de una casa de la parroquia de Priegue del municipio pontevedrés de Nigrán. Los cuadros son un "Gouache" de la epoca rosa del pintor, un retrato en madera de su prima Maria Ruiz, y un temple sobre tela con una figura inacabada.

El representante autorizado por la Asociación de Críticos de París para catalogar la obra de Picasso, Ramon Faraldo, ha manifestado que no existen dudas sobre la autoria de los cuadros, y que pertenecen a Picasso.

La adquisición de los cuadros tuvo su origen en el año 1920. cuando el párroco de Priegue fue requerido por el obispo de la diocesis para que pusiera en venta unas casas de su propiedad, situadas en una zona de Vigo poco acorde con la moral cristiana.

Figura 2. ABC (Sevilla) 23/11/1986.

\section{Descubiertas tres obras de Picasso en un trastero}

\author{
(1) \\ EFE \\ Santlago de Compostela - 23 NOV 1986 \\ Tres cuadros de Picasso se han encontrado en el trastero de una casa situada en \\ la parroquia de Priegue, del muncipio pontevedrés de Nigrán. Son un gouasche \\ de la época rosa del pintor, un retrato en madera de su prima María Ruiz y un \\ temple sobre tela coN una figura inacabada. Ramon Farraldo, representante \\ autorizado por la Asociación de Críticos de París para catalogar la obra de \\ Picasso, ha confirmado su autoría.Las obras fueron descubiertas recientemente \\ en un cuarto trastero de la casa del párroco de Priegue por sus herederos. La \\ adquisición de los cuadros, según el diario La Voz de Galicia, tuvo su origen en \\ 1920, cuando el párroco de Priegue fue requerido por el obispo de la diócesis \\ para que vendiera unas casas de su propiedad, situadas en una zona de Vigo \\ poco acorde con la moral cristiana. Poco después, el sacerdote viajó a París, \\ donde adquirió las obras por 28.000 pesetas.
}

Figura 3. El País 23/11/1986. 